\title{
Retención aguda de orina, "RAO", como presentación de quiste de uraco
}

\author{
C. Quicios Dorado, E. Fernández Fernández, I. Gómez García, D. García Flórez, \\ C. De Castro Guerin, A. Escudero Barrilero
}

Servicio de Urología. Hospital Ramón y Cajal. Madrid.

Actas Urol Esp 2005; 29 (9): 909-912

\section{RESUMEN}

RETENCIÓN AGUDA DE ORINA, "RAO “, COMO PRESENTACIÓN DE QUISTE DE URACO

$\mathrm{El}$ quiste de uraco esta presente aproximadamente en el $2 \%$ de los adultos, siendo su diagnostico difícil y secundario a las manifestaciones de su complicaciones. Presentamos un caso inusual de retención aguda de orina en un quiste de uraco, que debutó como dolor hipogástrico y anuria.

Palabras clave: RAO. Quiste de uraco. Talla vesical.

\section{ABSTRACT}

\section{URACHAL CYST PRESENTATED AS ACUTE URINARY RETENTION}

About $2 \%$ of adults have an urachal cyst. The diagnosis is usually made due to its clinical complications. We report an inusual case of acute urinary retention due to an urachal cyst, with hipogastric pain and anuria as initial syntoms.

Keywords: Acure urinary retention. Urachal cyst. Suprapubic catheter.

$\mathrm{E}^{1}$ uraco es el remanente embrionario de la alantoides. Esta aparece aproximadamente en el día 16 del desarrollo fetal y se extiende desde la porción craneoventral de la vejiga hasta la zona umbilical, por lo que inicialmente, la vejiga se extiende hasta el ombligo.

Hacia el $4^{\circ}-5^{\circ}$ mes de gestación la vejiga inicia el descenso hacia la pelvis, produciéndose la elongación de la alantoides, la cual se estrecha y oblitera progresivamente, formando el uraco ${ }^{1-4,5}$.

El uraco es un cordón fibroso que se extiende desde la parte anterior de la cúpula vesical hasta el ombligo y ocupa el espacio entre peritoneo y fascia transversalis.

Se diferencian 3 capas en el uraco: a) interna: epitelio de transición; b) submucosa: tejido conectivo; c) externa: músculo liso.

Aproximadamente el 50\% de los recién nacidos presentan permeabilidad del uraco, reduciéndose al $2 \%$ en el caso de los adultos ${ }^{2,3}$.
El quiste de uraco es una anomalía consecuencia de la obliteración de ambos extremos uracales (vesical y umbilical), persistiendo una cavidad en su parte media con contenido líquido seroso o mucinoso. Habitualmente son asintomáticos, diagnosticándose en la mayor parte de los casos de manera incidental, cuando presentan complicaciones. Una forma inusual de presentación es como retención aguda de orina (RAO), motivo por el que creemos de interés este caso.

\section{CASO CLÍNICO}

Mujer de 50 años con antecedentes de cólicos nefríticos de repetición y trombosis retiniana, que acude al Servicio de Urgencias por dolor lumbar derecho agudo irradiado a fosa iliaca derecha y náuseas sin vómitos. No presenta alteración del hábito intestinal. La paciente refiere ausencia de diuresis de 6 horas de evolución. A la exploración 
física destaca dolor e inflamación a nivel hipogástrico compatible con globo vesical, así como dolor en fosa renal derecha y puño percusión renal bilateral negativa. Analíticamente presenta hemograma, bioquímica y hemostasia dentro de límites normales y en el sistemático de orina escasa bacteriuria, hematíes aislados y leucocitos aislados. Se realiza radiografía simple de abdomen centrada en vías urinarias sin alteraciones destacables y ecografía urológica en la que se observan ambos riñones sin alteraciones destacables y vejiga con gran globo vesical, muy replecionada.

Ante los hallazgos y con probable diagnóstico de RAO se decide colocación de sonda vesical, no consiguiendo evacuar el globo vesical tras varios intentos. Se coloca cistostomía suprapúbica, saliendo gran contenido vesical y mejorando el cuadro clínico de la paciente.

A los tres días del ingreso se realiza cistouretrografía miccional seriada (CUMS) en la que se evidencia 2 cavidades vesicales, encontrándose en la superior la talla vesical y en la inferior la sonda vesical. La cistografía es compatible con gran divertículo vesical o gran quiste del uraco comunicado con vejiga (Fig. 1). Posteriormente se realiza TAC abdominopélvico demostrando talla vesical en cavidad intraperitoneal.

La paciente presenta buena evolución con débito cero por talla a los dos días del ingreso, retirándose tras un día pinzada. Posteriormente se retira sonda vesical presentando mínimas molestias al orinar. Se realiza estudio urodinámico (EUD) rellenándose vejiga con características normales sin evidenciarse imagen compatible con divertículo vesical en el vídeo tras la repleción a través de sonda vesical, no consigue micción espontánea en bipedestación y consigue micción sentada sin vídeo con prensa. No residuo. En ecografía con vejiga vacía se aprecia imagen hipogástrica de aproximadamente $4 \mathrm{~cm}$ en posición cercana a imagen posiblemente correspondiente con vejiga poco replecionada. No colecciones. Por último se realiza cistoscopia sin observar divertículo vesical ni lesiones en pared vesical.

Se decide intervención quirúrgica realizándose laparotomía exploradora sin evidenciar cavidad a repleción, extirpándose el uraco con pastilla vesical y mioma uterino, sin complicaciones. El estu-

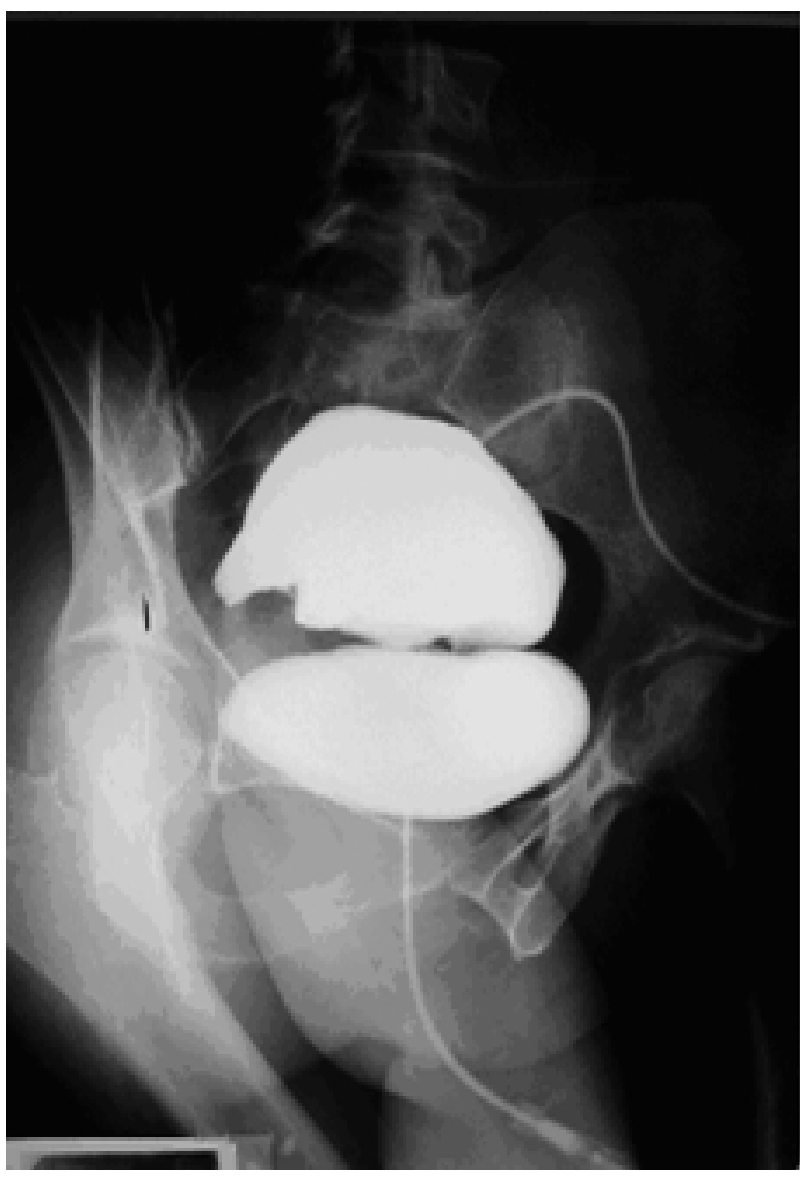

FIGURA 1

dio histológico informa conducto uracal sin lesiones histológicas significativas, pared vesical con cambios inflamatorios crónicos y leiomioma. La paciente presenta un postoperatorio satisfactorio, con CUMS al alta sin fugas, y con diagnóstico final de quiste de uraco (Fig. 2).

\section{DISCUSIÓN}

El uraco es un cordón fibroso, remanente embriológico de la alantoides, que discurre entre la parte anterior de la cúpula vesical y el ombligo.

Las alteraciones del uraco son infrecuentes y variadas, siendo las más frecuentes las congénitas (secundarias a obliteración incompleta), y en menor grado las adquiridas (secundarias a repermeabilidad del canal uracal). Destacamos:

1. Uraco permeable congénito: obliteración parcial del uraco desde ombligo a cúpula vesical que se traduce en comunicación permanente entre ambos. 


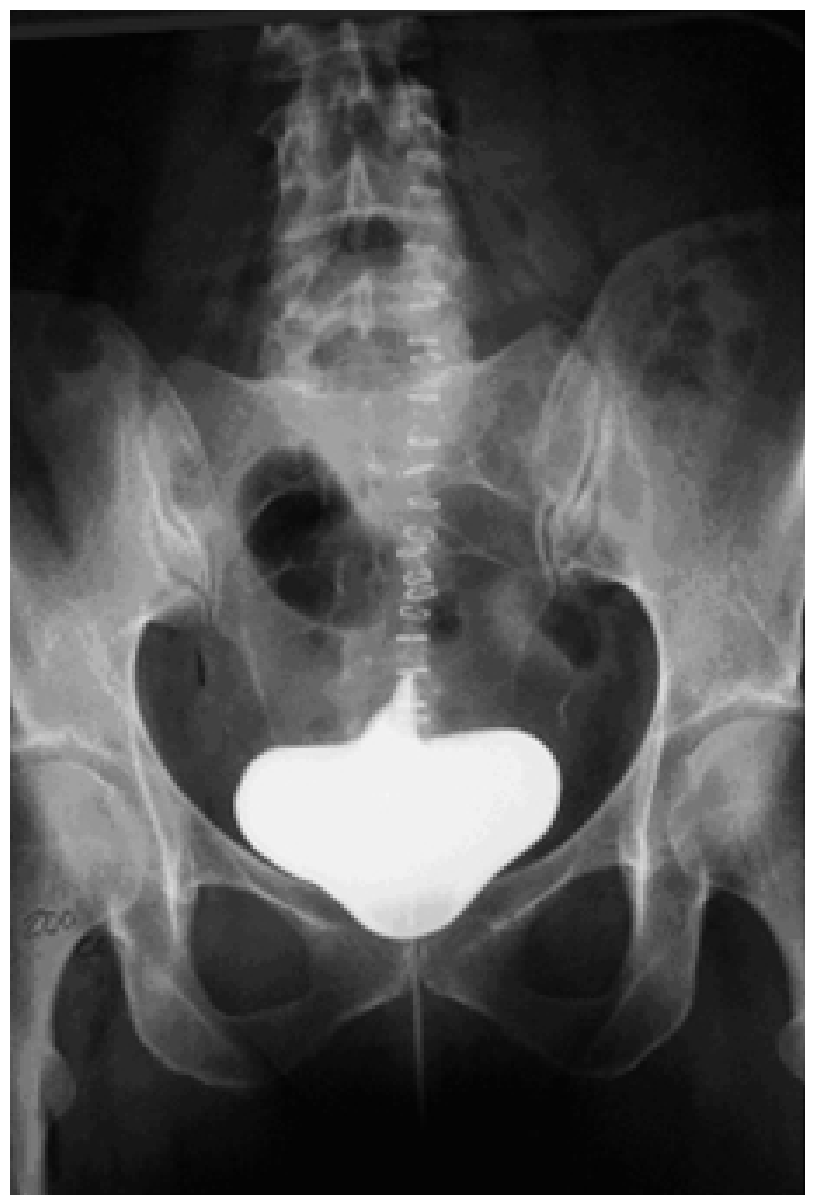

FIGURA 2

2. Seno uracal: obliteración del extremo inferior con dilatación y apertura del uraco a nivel umbilical.

3. Guiste uracal: obliteración de los dos extremos persistiendo la luz en la parte media.

4. Divertículo del uraco: obliteración del extremo superior, con comunicación entre uraco y vejiga. Se asocia con el Síndrome de Prune-Belly ${ }^{3,4}$.

El quiste de uraco se forma como consecuencia de la descamación y degeneración del epitelio uracal. Se sitúa fundamentalmente en el tercio inferior del uraco ${ }^{4,6-8}$. Con frecuencia persiste la comunicación entre uraco y vejiga lo que favorece la infección bacteriana.

Su diagnostico es difícil debido a su baja incidencia, ausencia de signos y síntomas específicos, y por la posibilidad de simular diferentes cuadros abdominales ${ }^{6,7}$.

Normalmente asintomático, se diagnostica cuando presenta complicaciones, destacando: infección, litiasis, repermeabilización, RAO y degeneración maligna. Ésta última es una entidad rara (menos del $0,5 \%$ de tumores vesicales) y de curso clínico indolente por su situación extraperitoneal, que hace que su diagnóstico sea tardío, encontrando habitualmente invasión local y metástasis. La variedad más frecuente son los adenocarcinomas, fundamentalmente de tipo mucinoso, y se sospecha ante la presencia de masa palpable en línea media infraumbilical y hematuria ${ }^{4,5}$. Se presenta comúnmente en varones entre 40-60 años. Un dato importante en su diagnostico son las calcificaciones, de tal forma que una masa situada en línea media supravesical con calcificaciones en su interior es altamente sugestiva de carcinoma de uraco $^{3-5}$. El TAC nos dará el diagnostico definitivo ${ }^{3-5}$, y nos informará del componente intra y extravesical así como la afectación tumoral de las estructuras adyacentes.

La complicación más habitual es el quiste de uraco infectado (piouraco), que aparece fundamentalmente en adultos jóvenes. El agente bacteriano más frecuentemente aislado es el Staphilococo Aureus, de origen cutáneo siendo la colonización vía descendente. Otros gérmenes aislados son las enterobacterias, colonizando el quiste por vía ascendente a través de la comunicación con la vejiga ${ }^{3,5,6}$.

Los signos y síntomas del quiste infectado son: dolor abdominal bajo, fiebre, alteraciones de la micción y masa palpable en hipogastrio, sospechándose incluso con orina clara ${ }^{1}$.

Entre las complicaciones ${ }^{1,3,5}$ del quiste de uraco infectado tenemos: rotura a la cavidad peritoneal con peritonitis secundaria, fístulas entéricas, y hernia incarcerada por atrapamiento de asa intestinal en interior del quiste ${ }^{9,10}$ (complicaciones éstas más frecuentes en adultos que en niños).

Dentro de los métodos diagnósticos destaca la ecografía como primera elección. El TAC nos aportara información relativa a la extensión del quiste y compromiso de otros órganos, siendo fundamental para establecer el diagnostico diferencial con adenocarcinoma de uraco ${ }^{4,5,7,8}$.

La cistografía permite comprobar la posible comunicación entre uraco y vejiga así como la existencia de alteraciones vesicales asocia$\operatorname{das}^{1,3,8}$. 
Otras pruebas útiles son la cistoscopia, quistografía, fistulografía y $\mathrm{RMN}^{5,7,8}$.

La principal patología que nos plantea en este caso diagnóstico diferencial con quiste de uraco es el divertículo vesical. Éste puede ser congénito o adquirido ${ }^{11}$. El primer caso es raro, debido a debilidad congénita del músculo detrusor. Es característico de la infancia, solitario y gigante, y suele manifestarse con disminución progresiva del calibre del chorro miccional previo al episodio de $\mathrm{RAO}^{12,13}$. El divertículo vesical adquirido se produce generalmente por elevada presión intravesical debido a obstrucción infravesical o a vejiga neurógena. Suelen ser múltiples, con historia de retención urinaria crónica ${ }^{14}$. En el diagnóstico es útil la ecografía, cistoscopia (en la que se identifica el divertículo) y la cistografía (generalmente confirma reflujo vesicodiverticular y el vaciamiento del divertículo durante la micción) ${ }^{11-14}$.Nuestra paciente no presentaba historia previa de dificultad miccional, y dada la ausencia de identificación de divertículo vesical en la cistoscopia asî como en la exploración quirúrgica, descartamos dicha patología.

El tratamiento definitivo consiste en la extirpación total del quiste junto con los dos extremos uracales y un rodete de cúpula vesical, con el fin de evitar recurrencias (que se producen en un $30 \%$ aproximadamente en caso de no extirpación) y posible malignización (menos de un 0,01\%). En caso de infección del quiste es recomendable realizar drenaje percutáneo del mismo junto con tratamiento antibiótico hasta control de la infección, para, en un segundo tiempo proceder a la extirpación quirúrgica ${ }^{2,3,5,6}$. En la actualidad el abordaje laparoscópico constituye la técnica quirúrgica de elección para el tratamiento del quiste de uraco $^{8,10,15,16}$.

\section{REFERENCIAS}

1. Gómez Parada J, Puyol Pallas JM: Quiste infectado de uraco: a propósito de un nuevo caso. Arch. Esp Urol 2001; 54(7):722-725
2. Kilani Elmasri S, Albors Valls L, Monsalve Rodríguez M, Gómez Cisneros S, Parra Mountaner L, García Alonso J. Quiste uracal infectado en adultos. Actas Urol Esp 1994; 18 (4):312-314.

3. Pereira Arias J.G, Gutiérrez Díez J.Mª , Ateca Díaz-Obregón R, et al. Quiste piouracal. Un diagnóstico a tener en cuenta. Actas Urol Esp 1998;22(3):257-261.

4. Jeong-Sik Yu, Ki Whang Kim, Hwa-Jin Lee, y cols. Urachal remant diseases: Spectrum of CT and US findings. RadioGraphics 2001;21:451-461.

5. Cilento B, Bauer B, Retik A, y cols: Urachal anomalies: defining the best diagnostic modality. Urology 1998;52: 120-122.

6. Flanagan D, Mellinger J: Urachal-Sigmoid fistula in an adult male. Am Surg 1998 Aug;64 (8):762-763.

7. Azurmendi Sastre V, Llarena Ibarguren R, Lozano Ortega J.L, Martín Bazaco J, Pertusa Peña C. Quiste de uraco. Estado actual. Arch. Esp Urol 2003;56(9):999-1004.

8. Muro Bidaurre I, Sanz Jaka J.P, Rekarte J.A, y cols: Quiste de uraco. Arch. Esp Urol 1998; 51(7 ):726-728.

9. Toshiyuki Yamazaki, Yasuo Sakai, Katsuyoshi Hatakeyama. Urachal Hernia. An unusual intra-abdominal hernia caused by incarceration into a urachal cys". Digestive diseases and Sciences 2000;45 (12):2365-2366.

10. Cadeddu J, Boyle K, Fabrizzio M, y cols. Laparoscopic management of urachal cyst in adulthood. The Journal of Urology 2000;164:1526-1528.

11. Doehn C, Baumgartel M, Fornara P, Jocham D. The largest diverticulum ever?. The Journal of Urology 1999;162(3): 793-794.

12. Shukla A.R, Bellah R.A, Canning D.A, Carr M.C, Snyder H.M, Zderic S.A Giant bladder diverticula causing bladder outlet obstruction in children. The Journal of Urology. 2004;172(5): 1977-1979.

13. Zia-Ul-Miraj M: Congenital bladder diverticulum: a rare cause of bladder outlet obstruction in children. The Journal of Urology 1999;162(11):2112.

14. Safir M.H, Gousse A.E, Raz S: Bladder diverticula causing urinary retention in a woman without bladder outlet obstruction. The Journal of Urology 1998;160(6):21462147.

15. Fried Siegel J, Winfield H, Valderrama E, y cols: Laparoscopic excision of urachal cyst. The Journal of Urology 1994;151:1631-1633.

16. Lorion J: Laparoscopic removal of urachal cyst. The Journal of Urology 1994 April;151:1006-1007.

Dra. C. Quicios Dorado

C/ Tramontana , $481^{\circ} \mathrm{A}$

Prado de Somosaguas

28223, Pozuelo de Alarcón (Madrid)

e-mail: quicios@yahoo.es

(Trabajo recibido el 5 de abril de 2005) 